\title{
Standardized ethanol extract, essential oil and zerumbone of Zingiber zerumbet rhizome suppress phagocytic activity of human neutrophils
}

\author{
Nabilah Mohammad Yaqoob Akhtar ${ }^{1}$, Ibrahim Jantan ${ }^{2 *}$ (D, Laiba Arshad ${ }^{3}$ and Md. Areeful Haque ${ }^{4}$
}

\begin{abstract}
Background: Zingiber zerumbet rhizome and its bioactive metabolites have previously been reported to exhibit innumerable pharmacological properties particularly anti-inflammatory activities. In the present study, the 80\% ethanol extract, essential oil and zerumbone of Z. zerumbet rhizomes were explored for their in vitro immunosuppressive properties on chemotaxis, CD11b/CD18 expression, phagocytosis and chemiluminescence of isolated human polymorphonuclear neutrophils (PMNs).

Methods: The extract was analyzed quantitatively by performing a validated reversed phase high performance liquid chromatography (RP-HPLC). Zerumbone was isolated by chromatographic technique while the essential oil was acquired through hydro-distillation of the rhizomes and further analyzed by gas chromatography (GC) and GCMS. Chemotaxis assay was assessed by using a 24-well cell migration assay kit, while CD18 integrin expression and phagocytic engulfment were measured using flow cytometry. The reactive oxygen species (ROS) production was evaluated by applying lucigenin- and luminol-enhanced chemiluminescence assays.
\end{abstract}

Results: Zerumbone was found to be the most abundant compound in the extract $(242.73 \mathrm{mg} / \mathrm{g})$ and the oil (58.44\%). Among the samples tested, the oil revealed the highest inhibition on cell migration with an $I C_{50}$ value of $3.24 \mathrm{\mu g} / \mathrm{mL}$. The extract, oil and zerumbone showed moderate inhibition of CD18 integrin expression in a dosedependent trend. Z. zerumbet extract showed the highest inhibitory effect on phagocytic engulfment with percentage of phagocytizing cells of 55.43\% for PMN. Zerumbone exhibited strong inhibitory activity on oxidative burst of zymosan- and PMA-stimulated neutrophils. Zerumbone remarkably inhibited extracellular ROS production in PMNs with an $I_{50}$ value of $17.36 \mu \mathrm{M}$ which was comparable to that of aspirin.

Conclusion: The strong inhibition on the phagocytosis of neutrophils by Z. zerumbet extract and its essential oil might be due the presence of its chemical components particularly zerumbone which was capable of impeding phagocytosis at different stages.

Keywords: Zingiber zerumbet, Zerumbone, Essential oil, Immunosuppressive effects, Phagocytic activity, Human neutrophils

\footnotetext{
* Correspondence: profibj@gmail.com

${ }^{2}$ School of Pharmacy, Faculty of Health and Medical Sciences, Taylor's

University, Lakeside Campus, 47500 Subang Jaya, Selangor, Malaysia

Full list of author information is available at the end of the article
}

(c) The Author(s). 2019 Open Access This article is distributed under the terms of the Creative Commons Attribution 4.0 International License (http://creativecommons.org/licenses/by/4.0/), which permits unrestricted use, distribution, and reproduction in any medium, provided you give appropriate credit to the original author(s) and the source, provide a link to the Creative Commons license, and indicate if changes were made. The Creative Commons Public Domain Dedication waiver (http://creativecommons.org/publicdomain/zero/1.0/) applies to the data made available in this article, unless otherwise stated. 


\section{Background}

The immune system is a sophisticated network of subsystems involving the coordination of various cells, proteins and chemical signals against infectious diseases. This preeminent system is classified into innate immunity (nonspecific) and adaptive immunity (acquired or specific). Phagocytosis is the host's defense mechanism which acts as the essential component of a carefully orchestrated cascade of events in the innate immunity. Professional phagocytes like neutrophils, macrophages and monocytes are the main line of defense which perform various functions in an inflammation or immune responses. These functions include interacting, identifying, capturing foreign particles and eliminating pathogens which invades the body. The most plentiful type of leukocytes residing in the blood are the polymorphonuclear neutrophils (PMNs) which are the earliest to migrate from the blood to infected sites for eradicating pathogens and removing cellular debris [1]. Predominantly, there are four steps in the phagocytosis process involving the phagocytes, namely chemotaxis, adhesion, engulfment and degradation via respiratory burst. Upon the invasion of pathogenic micro-organisms, foreign particles and events in the human body, the initial response in the first few hours plays a significant and critical role which is responsible for the consequence of the infection [2].

In a healthy individual, the activation of the immune system as a defense mechanism demonstrates the capability of maintaining homeostasis in the body. However, uncontrolled reactions resulting from impaired immune system functions can lead to tissue damage and disorders including hypersensitivity (overactive immune response), immunodeficiency (ineffective immune response) and autoimmunity (improper reaction to self) [2, 3]. Many immunostimulants and immunosuppressants in current clinical uses have major limitations due to their cytotoxicity causing severe adverse effects including nephrotoxicity, hepatotoxicity, hypertension, gastrointestinal toxicity, metabolic toxicity, and affecting rapidly growing cells [4]. Due to this setback, the usage of plant-derived herbal medicines and compounds is gaining interest among researchers in the development of safer and potent immunomodulating agents $[5,6]$. Compounds with immunomodulating potential usually come from plants' secondary metabolites including flavonoids, isoflavonoids, phytosterols, sesquiterpenes, indoles, polysaccharides, alkaloids, tannins and glucans $[7,8]$.

Zingiber zerumbet (L.) Roscoe ex Sm. (Family: Zingiberaceae) is widely distributed in all tropical regions especially in Southeast Asia, Pacific and Oceania. The rhizomes of the plant have been consumed as spices and used traditionally to treat various immune-inflammatory related disorders [9]. Numerous compounds have been isolated from $Z$. zerumbet which serve as potent and dependable medicinal candidates for innumerable disorders.
Among the compounds, the most isolated and utilized bioactive metabolite is zerumbone [10-12]. Previous studies indicated that the plant possessed many pharmacological activities including immunomodulatory, anti-inflammatory, antioxidant, antinociceptive, anticancer and antibacterial [13-15]. Recently, we reported that $Z$. zerumbet extract (ZZE) and zerumbone (ZER) demonstrated inhibitory effects against inflammation and related disorders pertaining to the immune system through the suppression of several pro-inflammatory markers via the MyD88-dependent NF$\kappa \mathrm{B}$, MAPKs, and PI3K-Akt activation $[9,11]$. The present study was the first to be performed in determining the activity of the standardized extract of $Z$. zerumbet including its essential oil (ZZEO) and marker compound, ZER on the four steps of phagocytosis in human neutrophils.

\section{Methods}

\section{Chemicals and reagents}

Serum opsonized zymosan A (Saccharomyces cerevisiae suspensions and serum), lipopolysaccharide (LPS), lucigenin (10,10' -dimethyl-9,9' -biacridinium, dinitrate), luminol (3aminophthalhydrazide), Hanks Balance Salt Solutions (HBSS), fluorescein isothiocyanate (FITC)-labelled opsonized Escherichia coli, trypan blue, ibuprofen (purity 99\%), acetylsalicylic acid (purity 99\%), phorbol 12-myristate 13acetate (PMA), phosphate buffer saline tablet (PBS), and dimethylsulfoxide (DMSO) were acquired from Sigma ( $\mathrm{St}$ Louis, MO, USA). ZER (Sigma, St Louis, USA) standard with $98 \%$ purity was used as marker compound for quantitative determination of compounds present in the extract by high performance liquid chromatography (HPLC). Chemiluminescence measurements were performed on a Luminoskan Ascent luminometer (Thermo Scientific, UK). RPMI1640, fetal bovine serum (FBS), cytoselect 24-well cell migration assay kits, penicillin, streptomycin were purchased from Cell Biolabs, Inc. (CA, USA). The phagotest kit was procured from Glycotope Technology, Germany. Immunoglobulin G-FITC, FITC-conjugated CD18, APC-conjugated CD11b and FACS lysing solution were acquired from BD Biosciences, USA. HPLC grade methanol and acetonitrile were purchased from E-Merck. Dichloromethane was used as a solvent. The essential oil obtained from hydrodistillation was dried with anhydrous $\mathrm{MgSO}_{4}$. A HPLC (Waters 2998) (Leitz Watzler, Germany), light microscope, a $\mathrm{CO}_{2}$ incubator (Shell Lab, USA), and a flow cytometer BDFACS Canto II equipped with $488 \mathrm{~nm}$ argon-ion laser were also utilized.

\section{Preparation of extract and isolation of zerumbone}

The whole plant of Zingiber zerumbet was obtained from Kuantan, Pahang, Malaysia in November 2016. The plant material was identified by a botanist, Dr. Abdul Latif Mohamad, at the Faculty of Science and Technology, Universiti Kebangsaan Malaysia (UKM), Malaysia and a 
voucher specimen (no: UKMHF137) was deposited at the Herbarium of UKM. The rhizomes of $Z$. zerumbet $(1.75 \mathrm{~kg})$ were ground, dried and macerated using $3 \mathrm{~L}$ of $80 \%$ ethanol ( 3 times) for $72 \mathrm{~h}$ at room temperature before being filtered by Whatman No.1 filter paper (Whatman, England). The filtrates were then pooled, collected and any residual solvent was removed by a rotary evaporator at $40{ }^{\circ} \mathrm{C}$ to obtain a dark brown extract. The extract was subsequently freeze-dried to acquire a crude gummy-like extract with a yield of $14.7 \%$ and stored at $4{ }^{\circ} \mathrm{C}$ for further use $[9,11]$. ZER was isolated according to the method of Haque et al. [11]. Briefly, the concentrated crude extract $(10 \mathrm{~g})$ was subjected to repeated column chromatography $(40-63 \mu \mathrm{m}, 3 \times 60 \mathrm{~cm})$ with $n$ hexane: ethyl acetate $(10,0-7: 3$ ratios, $v / v)$. The eluates collected were allowed to evaporate slowly from the solvent for re-crystallization. Upon repeated recrystallization from $n$-hexane-ethyl acetate, white crystals of $87.4 \mathrm{mg}$ of ZER $(0.87 \%)$ were obtained. The purity (>98\%) and identity of ZER were confirmed based on ESI-MS and NMR spectroscopy and its physicochemical property [11]. Figure 1 shows the chemical structure of ZER and Fig. 2 depicts ${ }^{13} \mathrm{C}$-NMR spectrum of ZER. Additional file 1: Fig. S1 and Additional file 2: Fig. S2 show ${ }^{1}$ HNMR and HRESI-MS spectra of the compound.

\section{Preparation of essential oil}

The fresh $Z$. zerumbet rhizomes were cleaned, cut into small pieces and dried under shade for three days. The dried material $(2.5 \mathrm{~kg})$ was subjected to hydrodistillation for $8 \mathrm{~h}$ in a Clevenger-type apparatus (WUTEG, Germany) to obtain $9.2 \mathrm{~mL}$ of light yellowish oil. The oil was dried over anhydrous magnesium sulphate to remove traces of moisture and kept at $4{ }^{\circ} \mathrm{C}$ until further use.

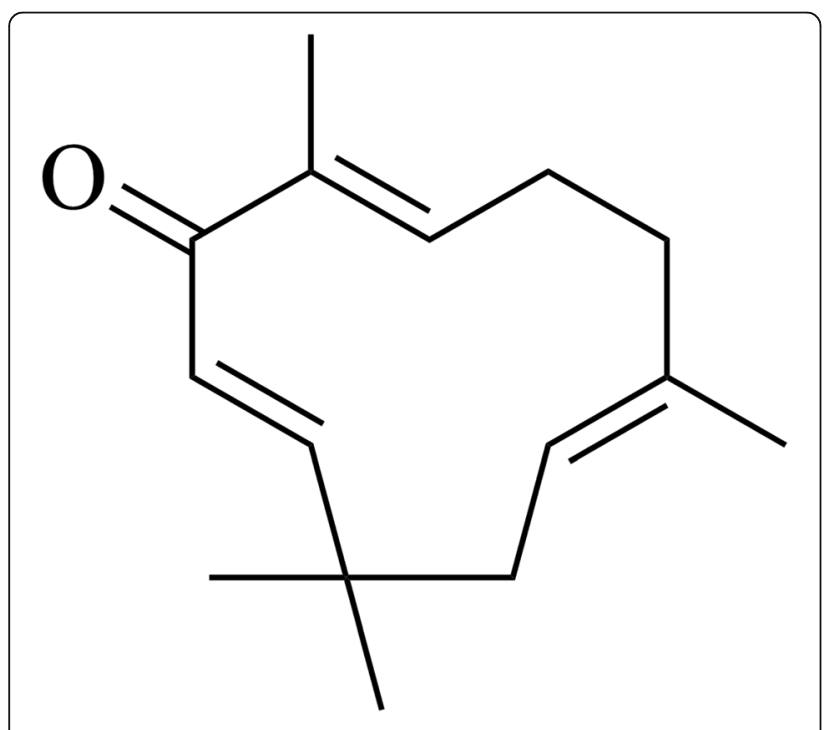

Fig. 1 Chemical structure of zerumbone

\section{GC and GC-MS analysis of the essential oil}

The analysis of $Z$. zerumbet essential oil (ZZEO) was performed by the Shimadzu GC-2010 with column DB-5 $(30 \mathrm{~m} \times 0.25 \mathrm{~mm}$ i.d, $1.0 \mu \mathrm{m}$ film thickness) equipped with a flame ionization detector (FID). The oil was dissolved in ethyl acetate and automatically injected in split mode with nitrogen as the carrier gas at a pressure of $50.0 \mathrm{~mL} / \mathrm{min}$ at a flow rate of $1.19 \mathrm{~mL} / \mathrm{min}$. The initial column temperature of the oven, set at $75.0^{\circ} \mathrm{C}$ for 10 min was gradually increased to $250^{\circ} \mathrm{C}$ at the rate of $3^{\circ} \mathrm{C} / \mathrm{min}$ for $5 \mathrm{~min}$. A homologous series of $n$-alkane standards ( $\mathrm{C} 9$ to $\mathrm{C} 22$ ) were additionally subjected within the same condition as the essential oil. The linear retention indices (RI) were calculated corresponding to the $n$ alkane standards $[16,17]$. The essential oil was also analyzed by GC-MS performed on an Agilent 7890A gas chromatograph (GC) directly coupled to the mass spectrometer system (MS) of an Agilent 5975C inert MSD with triple-axis detector. The model used was DB-5MSUI $(30 \mathrm{~m} \times 0.25$ i.d, $0.25 \mu \mathrm{m}$ thickness $)$ with helium as the carrier gas at a flow rate of $1.3 \mathrm{~mL} / \mathrm{min}$. The temperature of the oven, initially programmed at $75.0^{\circ} \mathrm{C}$ for $10 \mathrm{~min}$ was increased gradually at $3{ }^{\circ} \mathrm{C} / \mathrm{min}$ to $250^{\circ} \mathrm{C}$ and held for $5 \mathrm{~min}$. Peak identification in the GC chromatogram was carried out based on the MSD Chemstation and a library search was performed for all peaks by the NIST/EPA/NIH version 2.0 database (Agilent technologies). The compounds were also identified by comparison of calculated retention indices with literature values and co-chromatography of some constituents with authentic components on the DB 5 capillary column.

\section{HPLC analysis for standardization of $80 \%$ ethanol extract of Zingiber zerumbet rhizome}

Standardization of the plant extract has been performed as stated by Haque et al. [9]. Briefly, $3 \mathrm{mg}$ of $Z$. zerumbet $80 \%$ ethanol extract and $1 \mathrm{mg}$ of the reference standard (ZER) were dissolved in $1 \mathrm{~mL}$ of methanol and sonicated for $10 \mathrm{~min}$. The stock solutions were filtered through $0.45 \mu \mathrm{m}$ nylon filter membrane (Maidstone, Kent, UK). ZER (98\% purity) was purchased from Sigma, St. Louis, USA. Thereafter, the diluted solutions of the reference standards and extracts were analyzed using HPLC under the subsequent settings: column: reversed phase, C-18 column $(250 \mathrm{~mm} \times 4.6 \mathrm{~mm}$ i.d, $5 \mu \mathrm{m}$, Xbridge, Waters, Ireland), and detector: PDA (Waters 2998) with injection volume $20 \mu \mathrm{L}$ and wavelength $250 \mathrm{~nm}$. Gradient elution method was employed using solvent A (acetonitrile) and solvent $\mathrm{B}$ (water) as the mobile phase at a flow rate of $1.2 \mathrm{~mL} / \mathrm{min}$ for the analysis of the standard compound and extract. The initial composition for mobile phase was $65 \%$ solvent $\mathrm{A}$, then increasing to $70 \%$ of solvent $\mathrm{A}$ over 10 min followed by $75 \%$ solvent A and held for 16 min. Compound identification in the extract sample was 


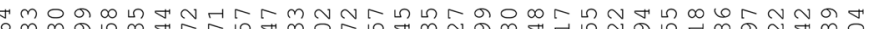

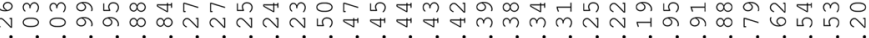

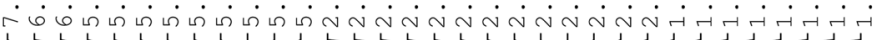

(1)

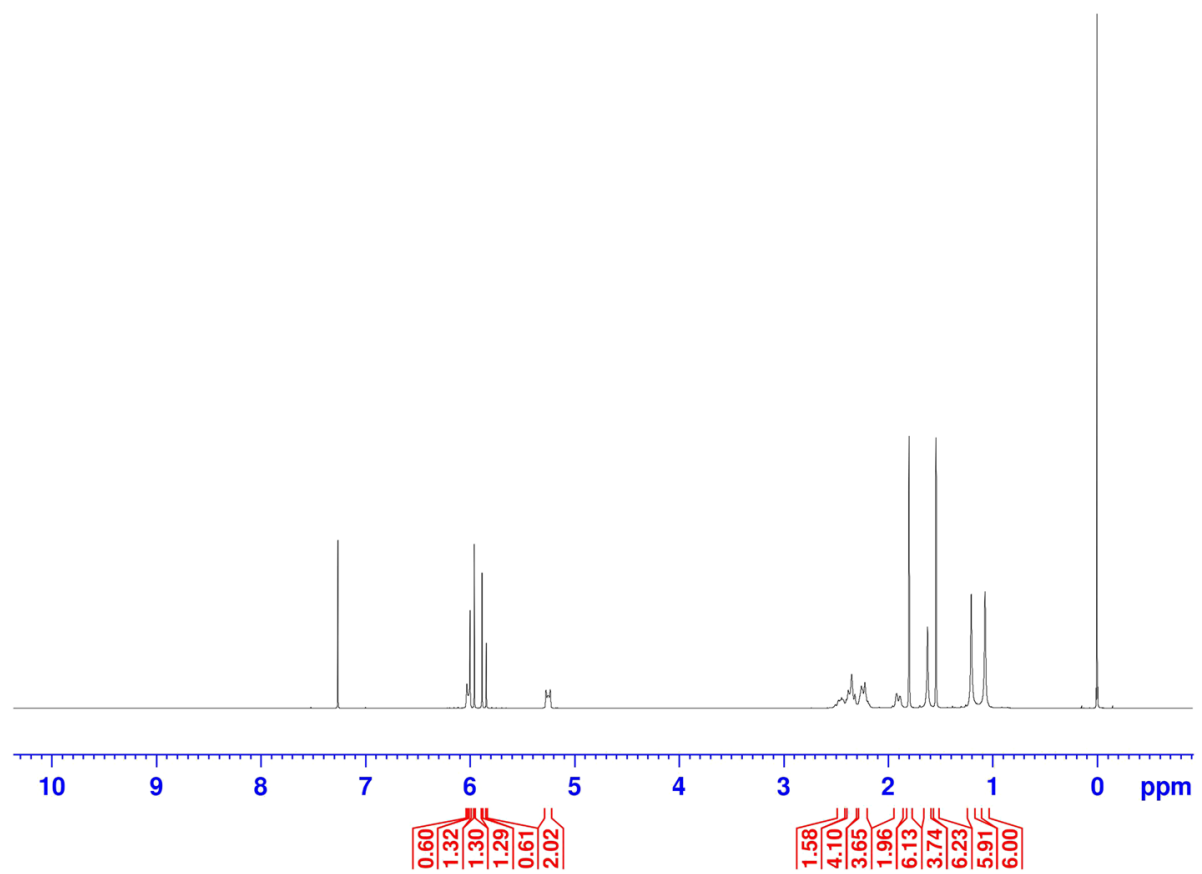

Fig. $2{ }^{13} \mathrm{C}$ NMR spectrum of zerumbone

done via comparison of the retention times and peak spectra of those acquired from the standard. Quantification of compound in the extract was determined from the standard curve equation plotted from four concentrations of the standard solution.

\section{Validation of HPLC method}

HPLC method was validated by determination of the precision, linearity, limits of detection (LOD) and quantification (LOQ). Linearity was determined from the correlation coefficient $\left(\mathrm{r}^{2}\right)$ obtained based on the calibration curve plotted from a range of concentrations of 125 to $1000 \mu \mathrm{g} / \mathrm{mL}$ of the standard. The precision of the HPLC method on repeatability and intermediate precision were computed as the relative standard deviation (RSD) from the injection of standard samples ranging from concentrations of 125 to $1000 \mu \mathrm{g} / \mathrm{mL}$. Each concentration was injected thrice per day (intraday precision) and on three separate days (interday precision). LOD and LOQ were calculated from the RSD and slope $(\mathrm{S})$ of the calibration curve by using the following equation: $\mathrm{LOD}=$ $3.3 \times(\mathrm{RSD} / \mathrm{S})$ and $\mathrm{LOQ}=10 \times(\mathrm{RSD} / \mathrm{S})$.

\section{Isolation of human polymorphonuclear neutrophils}

Fresh blood was attained by aseptic vein puncture as described by Arshad et al. [18] from healthy volunteers who were non-smokers, fasted overnight and not consuming any supplements or medications. Briefly, $10 \mathrm{~mL}$ whole blood with equal amount of HBSS were allowed to sediment for $30 \mathrm{~min}$ at room temperature. The separated plasma layer was layered onto lymphoprep gradient $(1077 \mathrm{mg} / \mathrm{mL})$ and centrifuged at $400 \times \mathrm{g}$ for $20 \mathrm{~min}$ at room temperature to allow neutrophils and erythrocytes settle at the bottom of the lymphoprep layer. One millilitre of cold distilled water was briefly added for red blood cells lysis followed by PBS before the mixture was centrifuged at $300 \times \mathrm{g}$ at $4{ }^{\circ} \mathrm{C}$ for $10 \mathrm{~min}$. Next, the supernatant was carefully aspirated and the sedimented pellet was suspended with HBSS for cell purification to a final concentration of $1 \times 10^{6}$ cells $/ \mathrm{mL}$. The Human Ethical Committee of Universiti Kebangsaan Malaysia (Approval no: UKM PPI/111/8/JEP-2017-335) approved the use of human blood in this study. Volunteers who participated in this study provided written informed consent for blood collection.

\section{Cell viability}

The cells were subjected to viability test using trypan blue exclusion method as described by Jantan et al. [19] to determine the cytotoxicity of samples. Briefly, $200 \mu \mathrm{L}$ of ZZE and ZZEO (3.13 to $100 \mu \mathrm{g} / \mathrm{mL}$ ) and ZER at 0.63 to $20 \mu \mathrm{g} / \mathrm{mL}$ (3.13 to $50 \mu \mathrm{M}$ ) were incubated in $5 \% \mathrm{CO}_{2}$ 
incubator at $37^{\circ} \mathrm{C}$ for $2 \mathrm{~h}$ with equal volume of cell suspensions $\left(1 \times 10^{6}\right.$ cells $\left./ \mathrm{mL}\right)$ in triplicates. After incubation, $20 \mu \mathrm{L}$ of the mixture was mixed with $20 \mu \mathrm{L}$ trypan blue. The blue dye uptake indicated cell death and cell viability percentage was determined with the aid of hemocytometer.

\section{Chemotaxis assay}

The inhibitory effect of the test samples towards PMN chemotaxis was measured as described by Arshad et al. [20] with slight adjustments. Chemotaxis assay was conducted by using Cytoselect 24-well cell migration kit based on the protocol set by the manufacturer (Cell Biolabs Inc.). The assay started off by adding $500 \mu \mathrm{L}$ of RPMI media comprising 10\% FBS as chemoattractant into the lower chamber. The cell suspension was prepared in serum-free media to a final concentration of 1.5 $\times 10^{6}$ cells $/ \mathrm{mL}$. The upper chamber containing polycarbonate membrane inserts with $3 \mu \mathrm{m}$ pore size filters was filled with $300 \mu \mathrm{L}$ of cell suspension mixed with test samples ranging from five serial dilution concentrations (ZZEO and ZZE: 40 to $2.5 \mu \mathrm{g} / \mathrm{mL}$ and ZER: 10 to $0.63 \mu \mathrm{g} / \mathrm{mL}$ ). The control wells consist of RPMI with $10 \%$ FBS and cells without any test samples. Ibuprofen was used as the positive control in relation to an earlier study demonstrating ibuprofen, a very efficacious NSAID in obstructing the migration of PMNs [21]. The 24-well tissue culture plate was allowed to incubate for $2.5 \mathrm{~h}$ in a $\mathrm{CO}_{2}$ incubator at $37^{\circ} \mathrm{C}$ to allow cell migration towards chemoattractant. The migrated cells sifted across the polycarbonate membrane and adhere at the surface underneath. The inserts were subsequently shifted to a clean well of $200 \mu \mathrm{L}$ cell detachment buffer to be incubated for $30 \mathrm{~min}$ at $37^{\circ} \mathrm{C}$ in $\mathrm{CO}_{2}$ incubator to allow cells to detach from the bottom of the membrane inserts. After incubation, the inserts were gently tilted inside the cell detachment solution to dislodge cells before the inserts were finally discarded. The migratory cells were lysed and stained by the addition of lysis buffer and CyQuant ${ }^{\circ}$ GR Fluorescent Dye. Finally, the migrated cells were quantified by determination of fluorescence as detected by Victor 2 plate reader (Perkin Elmer, Inc.)

\section{CD11b/CD18 integrin (mac-1) expression assay}

The method was carried out as explained by Harun et al. [22] with slight amendments. Aliquots of $100 \mu \mathrm{L}$ of heparinized whole blood and $20 \mu \mathrm{L}$ of each test sample were incubated at three respective concentrations (ZZEO and ZZE: 50 to $3.13 \mu \mathrm{g} / \mathrm{mL}$ and ZER: 10 to $0.63 \mu \mathrm{g} / \mathrm{mL}$ ) in $5 \% \mathrm{CO}_{2}$ for $30 \mathrm{~min}$ at $37^{\circ} \mathrm{C}$. Control tubes did not contain any test samples. The sample mixture was stimulated with LPS $(0.25 \mu \mathrm{g} / \mathrm{mL})$ and again incubated for 1.5 $h$. The reaction was then brought to a halt by concurrently transferring the tubes onto ice. Ten $\mu \mathrm{L}$ of APC- conjugated CD11b and FITC-conjugated CD18 as well as $10 \mu \mathrm{L}$ of IgG-FITC (negative control) was further added and all tubes were incubated for $1 \mathrm{~h}$ on ice. Thereafter, FACS lysing solution was added and the mixture was incubated in the dark for red blood cells lysis for $20 \mathrm{~min}$ before the tubes were centrifuged at 250 $\times \mathrm{g}$ at $4{ }^{\circ} \mathrm{C}$ for $5 \mathrm{~min}$. The supernatant was aspirated and cells were recurrently washed twice with PBS. Finally, cells were suspended in $500 \mu \mathrm{L}$ PBS before being analysed by flow cytometer to evaluate the expression of adhesion molecules. The mean fluorescence intensity of antibody-stained cells was recorded as percentage expression of CD11b and CD18.

\section{Phagocytosis assay}

Phagocytic activity was evaluated by performing the assay based on the manufacturer's protocol with the Phagotest assay kit (Glycotope Technology, Germany). In brief, $100 \mu \mathrm{L}$ heparinised peripheral whole blood with $20 \mu \mathrm{L}$ of test samples at three respective concentrations (ZZEO and ZZE: 50 to $3.13 \mu \mathrm{g} / \mathrm{mL}$; ZER: 10 to $0.63 \mu \mathrm{g} /$ $\mathrm{mL}$ ) and $20 \mu \mathrm{L}$ FITC-labelled E.coli at $37^{\circ} \mathrm{C}$ was incubated in a closed shaking water bath at $60 \mathrm{rpm}$ for 30 min, with the negative control remaining on ice. Cells without samples and engulfment activity at $37^{\circ} \mathrm{C}$ was used as positive control. Following incubation, all tubes were simultaneously shifted onto an ice box followed by addition of $100 \mu \mathrm{L}$ of ice-cold quenching solution to quench phagocytosis. After $3 \mathrm{~mL}$ of washing solution was added, the tubes were centrifuged at $250 \times \mathrm{g}\left(4{ }^{\circ} \mathrm{C}\right)$ for $5 \mathrm{~min}$ and the supernatant was discarded. Two $\mathrm{mL}$ of lysing solution was added after washing twice and followed by incubation in the dark for $20 \mathrm{~min}\left(37^{\circ} \mathrm{C}\right)$. After incubation, the tubes were centrifuged at the same speed and cells were lastly resuspended in $200 \mu \mathrm{L}$ of DNA staining solution. The phagocytic activity was analyzed via flow cytometry as the percentage of $E$. coli engulfment by phagocytizing neutrophils.

\section{Chemiluminescence assay}

Chemiluminescence assay was assessed as explained by Jantan et al. [19]. Briefly, $25 \mu \mathrm{L}$ of diluted whole blood in PBS (1:50) or $25 \mu \mathrm{L}$ PMN suspended in HBSS was incubated (at $37^{\circ} \mathrm{C}$ for $30 \mathrm{~min}$ ) with $25 \mu \mathrm{L}$ test samples at different serial dilution concentrations (ZZEO and ZZE: 40 to $2.5 \mu \mathrm{g} / \mathrm{mL}$; ZER: 10 to $0.63 \mu \mathrm{g} / \mathrm{mL}$ ) in 96 -well flat bottom microplates. The DMSO content in the mixture was altered to a final concentration of $0.6 \%$ to exclude solvent effect for chemiluminescence. Luminol, cells, $0.6 \%$ DMSO and HBSS++ acted as negative control while $25 \mu \mathrm{L}$ aspirin as positive control. Cells were then stimulated by $25 \mu \mathrm{L}$ serum opsonised zymosan (SOZ) followed by $25 \mu \mathrm{L}$ of luminol as a probe, or $25 \mu \mathrm{L}$ phorbol 12-myristate 13-acetate (PMA) followed by $25 \mu \mathrm{L}$ 
lucigenin. The final volume in each well was adjusted with HBSS to $200 \mu \mathrm{L}$. Thereafter, the microplates were incubated in a thermostatically controlled chamber of a luminoskan at $37^{\circ} \mathrm{C}$ for $50 \mathrm{~min}$. The readings shown were identified as reading luminoskan unit (RLU). The percentage of inhibition was calculated from the formula as follows:

$$
\text { Inhibition }(\%)=\frac{\left(\mathrm{RLU}_{\text {control }}-\mathrm{RLU}_{\text {sample }}\right) \times 100 \%}{\mathrm{RLU}_{\text {control }}}
$$

\section{Statistical analysis}

The results were represented as means \pm standard error of the mean (SEM) of the data obtained from triplicate experiments. The $\mathrm{IC}_{50}$ values of test samples were evaluated by Graph Pad Prism 5 Software based on at least three determinations. Statistical analysis was performed via one-way analysis of variance (ANOVA) for multiple comparisons followed by Dunnet's post hoc test using Statistical Analysis software SPSS11.5, and $p<0.05$ was regarded as statistically significant.

\section{Results}

Analysis of the components of essential oil

Hydrodistillation of $Z$. zerumbet rhizomes yielded 0.37\% of essential oil. The GC analysis of the essential oil identified 17 compounds. Based on Table 1, the main compound identified was 2,6,10-cycloundecatrien-1-one, 2,6, 9,9-tetramethyl-, also known as zerumbone (ZER) which constituted $58.44 \%$ of the oil. The relative amounts of individual components were based on peak areas obtained, without FID response factor correction.

\section{Quantification of chemical marker using RP-HPLC}

According to our earlier report, the chromatograms obtained from the reversed-phase HPLC column of the $80 \%$ ethanol extract of $Z$. zerumbet revealed several peaks with zerumbone as the major peak, at retention time of $9.745 \mathrm{~min}$ (Additional file 3: Fig. S3) [9]. Peak identification was performed by comparison with HPLC of the reference standard, ZER. The plotted calibration curves showed linearity corresponding to the correlation coefficient $\left(r^{2}\right)$ of 0.999 over a range of concentration from 125 to $1000 \mu \mathrm{g} / \mathrm{mL}$. The reproducibility of the HPLC result was demonstrated by good precision from the method employed conforming to the \%RSD values obtained as illustrated by the small values of standard deviation for retention time and responses of the marker compounds for both intraday and interday assay precisions. The \%RSD for interday and intraday assay precisions was analyzed as 0.93 and $1.53 \%$ disparately in respect to the retention time while 0.57 and $5.92 \%$ correspondingly in the case of peak area. The limit of detection (LOD) and limit of quantification (LOQ) for ZER was 0.117 and $0.355 \mu \mathrm{g} / \mathrm{mL}$, respectively. The small LOD and LOQ values established that the method used exhibited good sensitivity. The quantitative determination of

Table 1 Percentage composition of essential oil of Zingiber zerumbet

\begin{tabular}{|c|c|c|c|}
\hline Compound & Percentage composition (\%) & Kovat Index ${ }^{c}$ & Method of Identification \\
\hline a-Pinene & 1.27 & 939 & $a, b, c$ \\
\hline Camphene & 5.36 & 957 & $a, b, c$ \\
\hline a-Terpinene & 0.36 & 1018 & $a, b, c$ \\
\hline 1,8-Cineole & 1.70 & 1032 & $a, b, c$ \\
\hline$\beta$-Ocimene & 1.46 & 1038 & $a, b$ \\
\hline Nonen-1-ol & 1.75 & 1158 & $a, b$ \\
\hline Terpinen-4-ol & 1.53 & 1178 & $a, b, c$ \\
\hline$\beta$-Caryophyllene & 0.92 & 1420 & $a, b, c$ \\
\hline a-Humulene & 12.24 & 1458 & $a, b, c$ \\
\hline (E)-Nerolidol & 1.44 & 1564 & $a, b$ \\
\hline Caryophyllene oxide & 2.05 & 1581 & $a, b$ \\
\hline Humulene epoxide & 4.96 & 1608 & $a, b$ \\
\hline Caryophylla-4 (14),8 (15)-dien-5.alpha.-ol & 3.86 & 1642 & $a, b$ \\
\hline Calamenene & 0.49 & 1662 & $a, b$ \\
\hline a-Bisabolol & 1.03 & 1674 & $a, b$ \\
\hline Farnesol & 0.81 & 1708 & $a, b$ \\
\hline Zerumbone & 58.44 & 1734 & $a, b, c$ \\
\hline
\end{tabular}

a: analysis by mass fragmentation pattern in gas chromatography mass spectrometry (GC-MS)

b: Kovat indices on a DB5 column ( $1 \mu \mathrm{m}$ thickness, $30.0 \mathrm{~m}$ length, $0.25 \mathrm{~mm}$ diameter)

c: co-chromatography with authentic sample 
the major compound revealed ZER as the main constituent found in $Z$. zerumbet extract, which was calculated to be $242.73 \mathrm{mg} / \mathrm{g}$.

\section{Cell viability assay}

The cytotoxicity of ZZE, ZZEO and ZER from Z. zerumbet was evaluated on human whole blood and PMNs. After the cells were subjected to $2 \mathrm{~h}$ of incubation with test samples, the concentrations at which the cells were found viable $\geq 90 \%$ were below $50 \mu \mathrm{g} / \mathrm{mL}$ for ZZE and ZZEO, and $10 \mu \mathrm{g} / \mathrm{mL}(50 \mu \mathrm{M})$ for ZER, suggesting the samples were non-toxic for subsequent immunomodulating assays at these concentrations.

\section{Chemotaxis assay}

The effect of ZZE, ZZEO and ZER on PMN migration is shown in Fig. 3. As shown in the figure, all samples revealed a dose-dependent inhibitory effect. ZZEO showed the highest inhibitory activity on PMN chemotaxis with $\mathrm{IC}_{50}$ value of $3.24 \mu \mathrm{g} / \mathrm{mL}$, comparable to the positive control, ibuprofen with an $\mathrm{IC}_{50}$ value of $1.70 \mu \mathrm{g} / \mathrm{mL}$ $(8.25 \mu \mathrm{M})$. The second highest inhibition was shown by ZZE followed by ZER with $\mathrm{IC}_{50}$ values of 4.83 and $6.21 \mu \mathrm{g} / \mathrm{mL}(28.44 \mu \mathrm{M})$, respectively.

\section{CD11b/CD18 integrin (mac-1) expression assay}

The inhibitory effects of ZZE, ZZEO and ZER were analyzed on the expression of Mac-1 by using flow cytometer. As shown in Table 2 and Fig. 4, ZER at its highest concentration $(10 \mu \mathrm{g} / \mathrm{mL})$ was the most potent sample in suppressing $\mathrm{CD} 11 \mathrm{~b} / \mathrm{CD} 18$ surface expression with percentage expression $72.57 \%$ as compared to the untreated sample (positive control). ZZE and ZZEO both exhibited weak inhibition towards CD11b/CD18 expression on PMNs. All three samples of ZZE, ZZEO and ZER demonstrated a dose-dependent trend of inhibition in this assay.

\section{Phagocytosis assay}

The engulfment of opsonized E. coli by PMNs was evaluated using phagotest kit and analyzed by flow cytometry. The engulfment inhibitory activity at $37^{\circ} \mathrm{C}$ was used as a positive control and normal condition at $0{ }^{\circ} \mathrm{C}$ as a negative control. Based on results as shown in Table 3 and Fig. 5, at $50 \mu \mathrm{g} / \mathrm{mL}$ the highest inhibition of phagocytic activity was shown by ZZE which exhibited the highest engulfment inhibitory activity with percentage phagocytizing cells of $55.43 \%$, followed by ZZEO at $69.20 \%$. ZER at $10 \mu \mathrm{g} / \mathrm{mL}$ showed percentage of phagocytizing cells of $76.97 \%$.

\section{Chemiluminescence assay}

Preliminary screening was performed on the whole blood to investigate the effects of samples on respiratory burst upon activation by zymosan and PMA as illustrated in Table 4. The presence of intracellular ROS was detected by luminol, whereas lucigenin was used to detect extracellular ROS. For extracellular ROS production in whole blood induced by PMA, ZER showed an $\mathrm{IC}_{50}$ value of $6.83 \mu \mathrm{g} / \mathrm{mL}(31.25 \mu \mathrm{M})$ which was lower than that of aspirin with an $\mathrm{IC}_{50}$ value of $7.65 \mu \mathrm{g} / \mathrm{mL}$ $(42.46 \mu \mathrm{M})$. The samples were then further investigated for their effects towards ROS production in PMNs. For intracellular ROS production induced by zymosan, ZZE showed an $\mathrm{IC}_{50}$ value of $2.89 \mu \mathrm{g} / \mathrm{mL}$, comparable to the positive control, aspirin $(1.95 \mu \mathrm{g} / \mathrm{mL})$. ZER remarkably inhibited extracellular ROS production in PMNs with an $\mathrm{IC}_{50}$ value of $3.79 \mu \mathrm{g} / \mathrm{mL}(17.36 \mu \mathrm{M})$, comparable to the

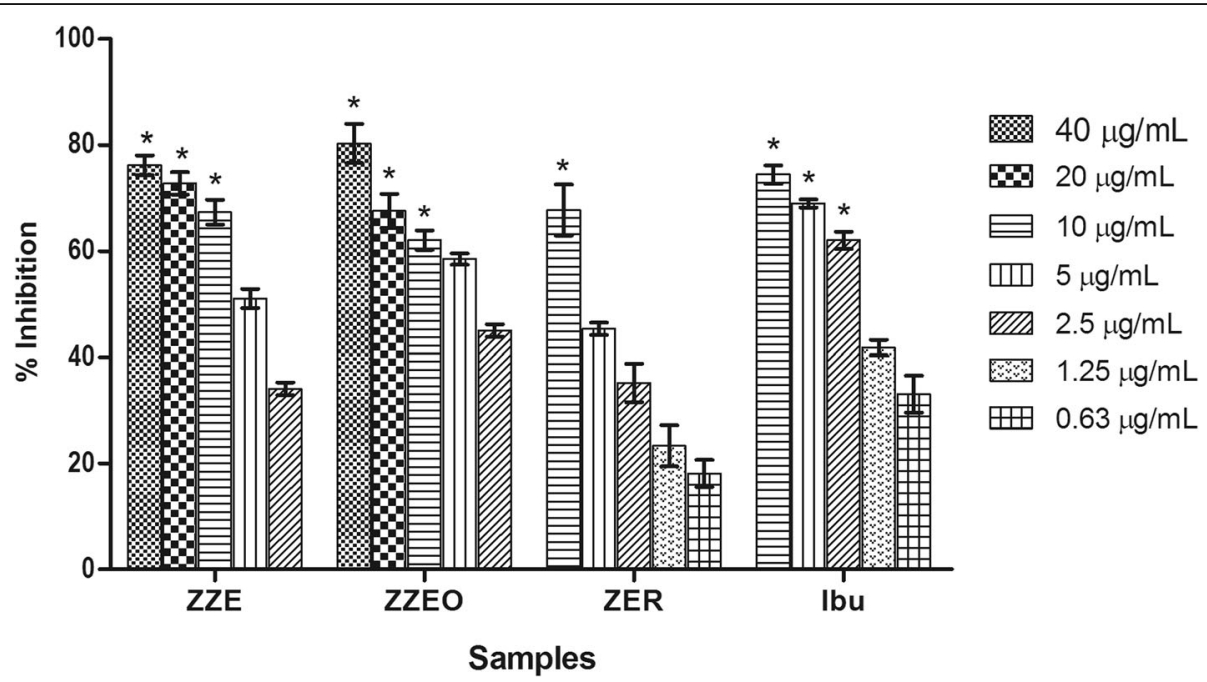

Fig. 3 Percentage inhibition of test samples on PMN chemotaxis presented as mean \pm SEM $(n=3)$. Data were analyzed by one-way ANOVA followed by Dunnet's post hoc test. Significance of differences with respect to control: * $p<0.05$ 
Table 2 Percentage of CD11b/CD18 expression activity (\%) of neutrophils at different concentrations of test samples derived from Zingiber zerumbet

\begin{tabular}{|c|c|c|c|}
\hline \multirow[t]{2}{*}{ Sample $(\mu \mathrm{g} / \mathrm{mL})$} & \multicolumn{3}{|c|}{ Concentration $(\mu \mathrm{g} / \mathrm{mL})$} \\
\hline & 50 & 12.5 & 3.13 \\
\hline Z. zerumbet extract (ZZE) & $87.67 \pm 0.59$ & $89.80 \pm 0.66$ & $96.23 \pm 1.63$ \\
\hline \multirow[t]{2}{*}{ Z. zerumbet essential oil (ZZEO) } & $91.03 \pm 0.63$ & $92.93 \pm 1.45$ & $96.10 \pm 0.85$ \\
\hline & 10 & 2.5 & 0.63 \\
\hline Zerumbone (ZER) & $72.57 \pm 6.45^{*}$ & $76.47 \pm 4.80^{*}$ & $86.77 \pm 1.77$ \\
\hline Positive control & $92.47 \pm 3.38$ & & \\
\hline
\end{tabular}

Data are presented as mean \pm SEM, $n=3$. Data were analyzed by one-way ANOVA followed by Dunnet's post hoc test. Significance of differences with respect to control: ${ }^{*} p<0.05$

$\mathrm{IC}_{50}$ value of aspirin which is $2.94 \mu \mathrm{g} / \mathrm{mL}(16.30 \mu \mathrm{M})$, suggesting the immunosuppressive potential of ZER.

\section{Discussion}

Inhibition of migration of phagocytes to the site of infection upon activation by endogenous or exogenous chemoattractants can account for part of the antiinflammatory activity of plant samples. The chemotaxis assay indicated that ZZEO was the most potent in inhibiting PMN chemotaxis comparable to the positive control, ibuprofen. The anti-inflammatory activity of $Z$. zerumbet is well supported by many previous studies. The methanol extract of $Z$. zerumbet had significantly inhibited the activities of cyclooxygenase (COX), lipoxygenase (LOX), myeloperoxidase (MPO) and nitric oxide synthase (iNOS) (lipopolysaccharide-induced) [23]. Also recent studies have shown that ZER significantly suppressed p38 MAPK, an enzyme crucial for neutrophil chemotaxis in LPS-stimulated macrophages [10, 24], thus may explain the inhibitory chemotactic migration effect as observed in this assay. In addition, GC and GCMS analysis of the oil revealed the presence of the monocyclic sesquiterpene, ZER as the major compound along with other compounds. $\alpha$-Pinene present in the oil has been shown in previous study to significantly reduce the migration of neutrophils reacting to chemoattractants, (a)

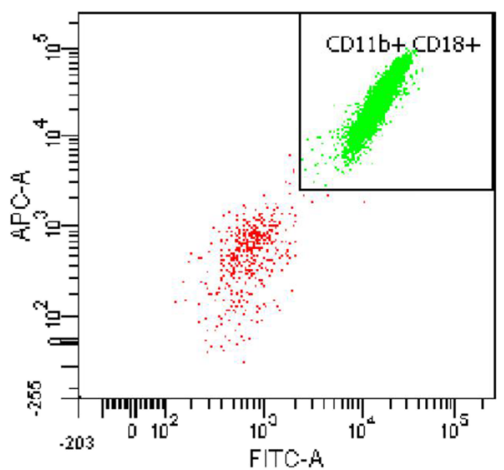

(c)

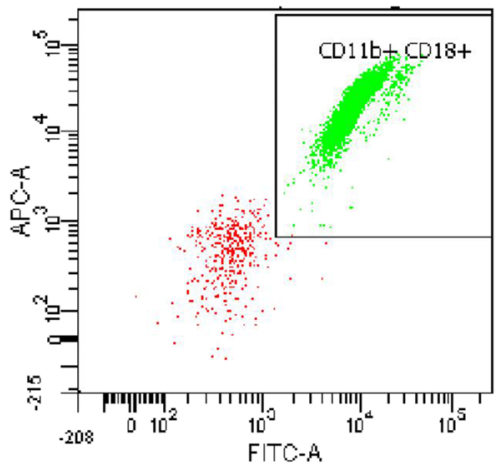

(b)

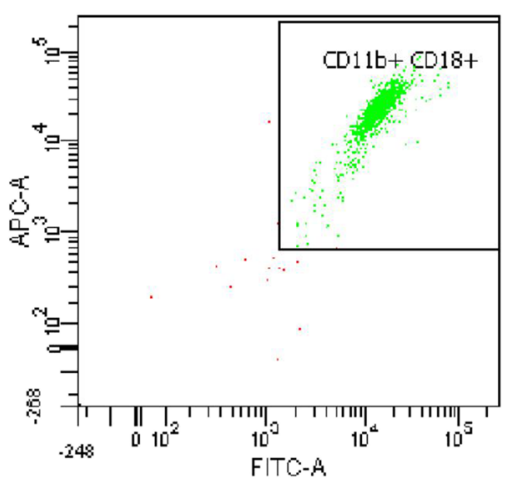

(d)

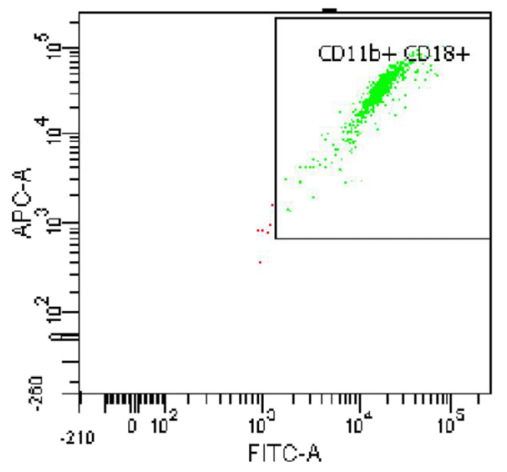

Fig. $4 \mathrm{CD} 1$ 1b/CD18 expression activity by neutrophils treated with test samples i.e., (a) positive control, (b) Z. zerumbet extract $(50 \mu \mathrm{g} / \mathrm{mL})$, (c) $Z$. zerumbet essential oil $(50 \mu \mathrm{g} / \mathrm{mL})$, (d) zerumbone $(10 \mu \mathrm{g} / \mathrm{mL})$ 
Table 3 Percentage of phagocytic activity (\%) of neutrophils at different concentrations of test samples derived from Zingiber zerumbet

\begin{tabular}{|c|c|c|c|}
\hline \multirow[t]{2}{*}{ Sample $(\mu \mathrm{g} / \mathrm{mL})$} & \multicolumn{3}{|c|}{ Concentration $(\mu \mathrm{g} / \mathrm{mL})$} \\
\hline & 50 & 12.5 & 3.13 \\
\hline Z. zerumbet extract (ZZE) & $55.43 \pm 0.77^{*}$ & $58.50 \pm 1.15^{*}$ & $59.30 \pm 0.68^{*}$ \\
\hline \multirow[t]{2}{*}{ Z. zerumbet essential oil (ZZEO) } & $69.20 \pm 0.74^{*}$ & $70.83 \pm 1.48^{*}$ & $77.87 \pm 1.18^{*}$ \\
\hline & 10 & 2.5 & 0.63 \\
\hline Zerumbone (ZER) & $76.97 \pm 1.15^{*}$ & $77.73 \pm 2.48^{*}$ & $79.70 \pm 3.08^{*}$ \\
\hline Positive control & $93.03 \pm 1.56$ & & \\
\hline
\end{tabular}

Data are presented as mean \pm SEM, $n=3$. Data were analyzed by one-way ANOVA followed by Dunnet's post hoc test. Significance of differences with respect to control: ${ }^{*} p<0.05$

fMLP and LTB4 [25]. Consistently, ZZEO in our present study revealed the presence of $\alpha$-pinene which may have contributed synergistically to produce a more pronounced effect when compared to zerumbone as a single compound. Various essential oils have demonstrated notable anti-inflammatory reaction by obstructing leukocyte migration towards the inflammatory focus $[26,27]$.

The binding of human leukocyte integrins (CD11a/ CD18, CD11b/CD18 and CD11c/CD18) to LPS triggers deleterious systemic inflammatory responses when released into blood circulation, causing organ damage [28]. The inhibition of CD11b/CD18 expression could be due to the inhibition of adhesion molecule expressions. Lipid A-like molecules were capable of deterring the stimulatory effect induced by LPS, thus reducing the upregulation of CD11b/CD18 surface expression and reduced the progress of inflammatory processes [28]. The CD11b/CD18 integrin expression assay showed that ZER was the most active in suppressing LPS binding site on human leukocytes. ZER has been shown to suppress NF$\mathrm{kB}$ signaling pathway [10], which regulates various immune and inflammatory genes expression involving cytokines and adhesion molecules [29]. Thus this may suggest that ZER was able to inactivate the expression of CD11b/CD18 integrins via NF-kB pathway.

The key receptors in phagocytosis are the Fc receptor and complement CR3 receptor. Fc-gamma receptors sense immunoglobulin-contained particles while complement (a)

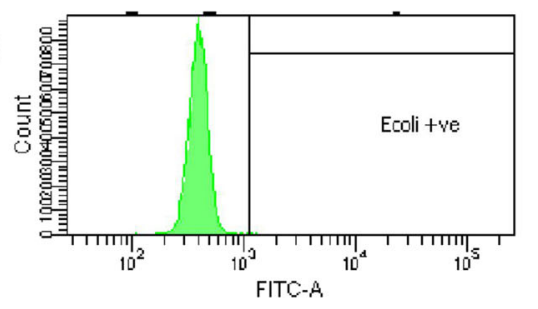

(c)

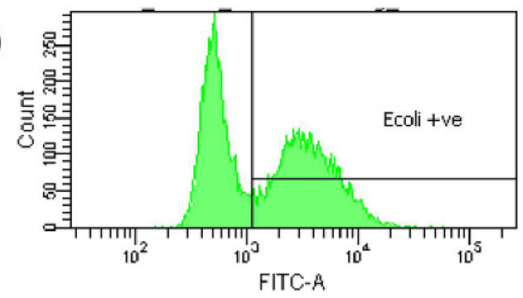

(b)

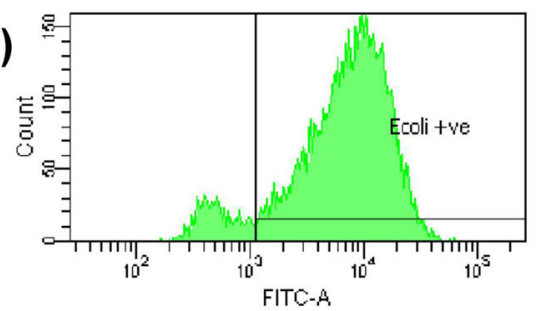

(d)

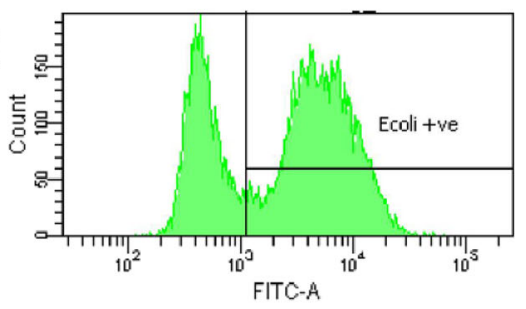

(e)

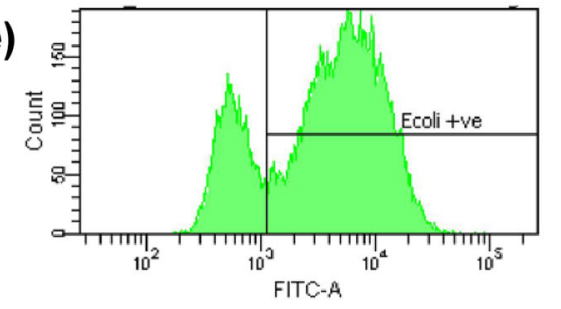

Fig. 5 E. coli engulfment by neutrophils treated with test samples i.e., (a) negative control, (b) positive control, (c) Z. zerumbet extract (50 $\mu \mathrm{g} / \mathrm{mL})$, (d) Z. zerumbet essential oil $(50 \mu \mathrm{g} / \mathrm{mL})$, (e) zerumbone $(10 \mu \mathrm{g} / \mathrm{mL})$ 
Table $4 \mathrm{IC}_{50}$ values $(\mu \mathrm{g} / \mathrm{mL})$ of ROS inhibitory activity of tested samples on human whole blood and PMNs

\begin{tabular}{|c|c|c|c|c|}
\hline \multirow[t]{2}{*}{ Samples } & \multicolumn{2}{|l|}{ Zymosan } & \multicolumn{2}{|l|}{ PMA } \\
\hline & Whole blood & PMNs & Whole blood & PMNs \\
\hline Z. zerumbet extract (ZZE) & $6.49 \pm 2.16$ & $2.89 \pm 0.98$ & $10.87 \pm 1.50$ & $14.87 \pm 2.70^{* * *}$ \\
\hline Z. zerumbet essential oil (ZZEO) & $8.71 \pm 1.37^{*}$ & $5.88 \pm 1.70$ & $11.63 \pm 1.78$ & $12.62 \pm 0.87^{* *}$ \\
\hline Zerumbone (ZER) & - & $\begin{array}{l}8.25 \pm 0.73^{*} \\
(37.77 \pm 3.38)\end{array}$ & $\begin{array}{l}6.83 \pm 0.68 \\
(31.25 \pm 3.10)\end{array}$ & $\begin{array}{l}3.79 \pm 0.24 \\
(17.36 \pm 1.08)\end{array}$ \\
\hline Aspirin & $\begin{array}{l}2.63 \pm 0.17 \\
(14.57 \pm 0.92)\end{array}$ & $\begin{array}{l}1.95 \pm 0.07 \\
(10.82 \pm 0.40)\end{array}$ & $\begin{array}{l}7.65 \pm 0.43 \\
(42.46 \pm 2.40)\end{array}$ & $\begin{array}{l}2.94 \pm 0.26 \\
(16.30 \pm 1.46)\end{array}$ \\
\hline
\end{tabular}

Data are presented as (mean $\pm \mathrm{SEM}, \mathrm{n}=3$ ). Data were analyzed by one-way ANOVA followed by Dunnet's post hoc test. IC ${ }_{50}$ values in $\mu M$ are shown in parentheses. Significance of differences with respect to control: ${ }^{*} p<0.05,{ }^{* *} p<0.01,{ }^{* * *} p<0.001$

receptors seek the particles opsonized by complement factors [30]. Fc receptors are expressed on neutrophils and functions to phagocytose and intracellular killing of opsonized pathogens. Fc receptor's responses can be obstructed by ROS inhibitors and inhibitors of the $\mathrm{H}_{2} \mathrm{O}_{2}$ myeloperoxidase-chloride system [31]. The results of this study indicated that ZZE has the highest inhibition of phagocytic activity. The results illustrate the inhibition of complement opsonized E. coli uptake may result from the suppression of the above-mentioned receptors on the PMNs by the plant samples.

Upon stimulation by opsonized SOZ or PMA, PMNs produced ROS which is generated through the NADPH oxidase complex. The plant samples were investigated for their inhibitory effects on the oxidative burst. Plant constituents possessing antioxidant properties demonstrate suppressive effect towards free radicals during oxidative burst. In this study, ROS production was determined upon stimuli with opsonized SOZ which stimulates neutrophils via surface complement receptor (CR3) and PMA which crosses the cellular membrane and binds to protein kinase $C$ independent of cell receptor interaction [32]. The high inhibitory activity shown by ZZE in luminol-amplified chemiluminescence is consistent with the results of previous study which studied the antioxidant activities of $Z$. zerumbet ethanol extract on hydroxyl radical scavenging assays and DPPH and demonstrating substantial radical scavenging activities due to high polyphenol, flavonoid and kaempferol contents in the extract [33]. ZER possesses an $\alpha, \beta$ unsaturated carbonyl group in its molecule and was effective in inhibiting PMA-induced oxidative burst. This finding is in accordance with Arshad et al. [7] where the $\alpha, \beta$-unsaturated carbonyl moiety of ZER might act as an antioxidant and was capable of being radical scavengers via covalent ligand binding to target proteins.

\section{Conclusion}

The outcome of the current study corroborated ZER as the major compound through HPLC quantitative and qualitative analysis of ethanol extract of $Z$. zerumbet. The hydrodistillation of essential oil of $Z$. zerumbet similarly revealed zerumbone as its major constituent. ZZEO showed the highest inhibitory effect followed by ZZE in chemotaxis assay. Meanwhile, for phagocytic engulfment and intracellular ROS production, ZZE showed the highest inhibitory effect whereas, extracellular ROS production was highly suppressed by ZER. Even though ZZE and ZZEO contained other constituents, ZER was the major contributor in inhibiting the respiratory burst stage. Correspondingly, other secondary metabolites present in ZZE and ZZEO might have acted synergistically with ZER, contributing towards the inhibitory effects. Therefore, the ethanol extract, essential oil and ZER from $Z$. zerumbet have the potential to be used as immunosuppressants to selectively inhibit the innate immune responses consecutively at different stages.

\section{Supplementary information}

Supplementary information accompanies this paper at https://doi.org/10. 1186/s12906-019-2748-5.

Additional file 1: Figure S1. ${ }^{1} \mathrm{H}$ NMR spectrum of zerumbone. Additional file 2: Figure S2. HRESI-MS spectra of zerumbone. Additional file 3: Figure S3. RP-HPLC chromatograms of (a) $80 \%$ ethanol extract of Zingiber zerumbet (b) zerumbone detected at $250 \mathrm{~nm}$.

\section{Abbreviations}

CD: Cluster of differentiation; COX: Cyclooxygenase; DCM: Dichloromethane; DMSO: Dimethylsulphoxide; DPPH: 2, 2-Diphenyl-1-Picrylhydrazyl; ESIMS: Electrospray ionization mass spectrometry; EtOAc: Ethyl acetate; FACS: Fluorescence activated cell sorting; FBS: Fetal bovine serum; FC: Complement factor; FID: Flame ionization detector; FITC: Fluorescein isothiocyanate; fMLP: formyl Methionine phenyl alanine; GC: Gas Chromatography; HBSS: Hank's balanced salt solution; HRESI-MS: Highresolution electrospray ionization mass spectrometry; IgG: Immunoglobulin G; LOD: Limit of detection; LOQ: Limit of quantification; LOX: Lipoxygenase; LPS: Lipopolysaccharide; LTB 4 : Leukotriene $\mathrm{B}_{4}$; Mac-1: Macrophage-1 antigen; MAPK: Mitogen-activated protein kinase; MPO: Myeloperoxidase; MS: Mass spectrometry; MS: Mass spectrometry; NF-kB: Nuclear factor-kappa B; NMR: Nuclear magnetic resonance; NSAID: Nonsteroidal Anti-inflammatory Drugs; PBS: Phosphate buffer saline; PI3K: Phosphoinositide 3-kinase; PMA: Phorbol myristate 13-acetate; PMNs: Polymorphonuclear neutrophils; RI: Retention indices; ROS: Reactive oxygen species; RP-HPLC: Reversed phase high performance liquid chromatography; RPMI: Roswell Park Memorial Institute; RSD: Relative standard deviation; SOZ: Serum opsonized zymosan; ZER: Zerumbone; ZZE: Zingiber zerumbet extract; ZZEO: Zingiber zerumbet essential oil 


\section{Acknowledgements}

The Ministry of Agriculture and Agro-based Industries, Malaysia is acknowledged for the support under the NKEA Research Grant Scheme (NRGS).

\section{Authors' contributions}

NMYA performed the experiment, analyzed and interpreted the data, and drafted the manuscript. IJ participated in the design, coordination of the study, analysis and interpretation of data. He revised the manuscript and approved the final version to be submitted for publication. LA and MAH were involved in the analysis and interpretation of data. All authors read and approved the final manuscript.

\section{Funding}

The study was funded by a grant from the Ministry of Agriculture and Agrobased Industries, Malaysia (NKEA Research Grant Scheme, grant no.

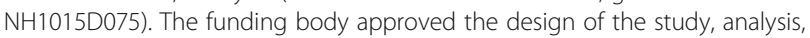
and interpretation of data, and publication of the manuscript.

\section{Availability of data and materials}

Materials used and data collected in this study are available from the corresponding author on reasonable request.

\section{Ethics approval and consent to participate}

The Human Ethical Committee of Universiti Kebangsaan Malaysia (Approval no: UKM PPI/111/8/JEP-2017-335) approved the use of human blood in this study. Volunteers who participated in this study provided written informed consent for blood collection.

\section{Consent for publication}

Not applicable.

\section{Competing interests}

The authors have no conflict of interest, financial or otherwise.

\section{Author details}

${ }^{1}$ Drug and Herbal Research Centre, Faculty of Pharmacy, Universiti Kebangsaan Malaysia, 50300 Kuala Lumpur, Malaysia. ${ }^{2}$ School of Pharmacy, Faculty of Health and Medical Sciences, Taylor's University, Lakeside Campus, 47500 Subang Jaya, Selangor, Malaysia. ${ }^{3}$ Department of Pharmacy, Forman Christian College (A Chartered University), Ferozeour Road, Lahore 54600, Pakistan. ${ }^{4}$ Department of Pharmacy, International Islamic University Chittagong, Chittagong 4318, Bangladesh.

\section{Received: 22 February 2019 Accepted: 7 November 2019}

\section{Published online: 21 November 2019}

\section{References}

1. Rosales C, Demaurex N, Lowell CA, Uribe-Querol E. Neutrophils: their role in innate and adaptive immunity. J Immunol Res. 2016;14(7): 660-7.

2. Marshall JS, Warrington R, Watson W, Kim HL. An introduction to immunology and immunopathology. Allergy, Asthma Clin Immunol. 2018; 14:49.

3. Rosenzweig SD, Holland SM. Phagocyte immunodeficiencies and their infections. J Allergy Clin Immunol. 2004;113:620-6.

4. Gilboa E, Berezhnoy A, Schrand B. Reducing toxicity of immune therapy using aptamer-targeted drug delivery. Cancer Immunol Res. 2015;3: 1195-200.

5. Mohamed SIA, Jantan I, Haque MA. Naturally occurring immunomodulators with antitumor activity: an insight on their mechanisms of action. Int Immunopharmacol. 2017;50:291-304.

6. Shukla S, Bajpai VK, Kim M. Plants as potential sources of natural immunomodulators. Rev Environ Sci Biol. 2014;13:17-33.

7. Arshad L, Jantan I, Bukhari SNA, Haque MA. Immunosuppressive effects of natural a, $\beta$-unsaturated carbonyl-based compounds, and their analogs and derivatives, on immune cells: A review. Front Pharmacol. 2017;8:22.

8. Patwardhan B, Gautam M. Botanical immunodrugs: scope and opportunities. Drug Discov Today. 2005;10:495-502.

9. Haque MA, Jantan I, Harikrishnan $\mathrm{H}$, Ghazalee S. Standardized extract of Zingiber zerumbet suppresses LPS-induced pro-inflammatory responses through NF-KB, MAPK and PI3K-Akt signaling pathways in U937 macrophages. Phytomedicine. 2019:54:195-205.

10. Haque MA, Jantan I, Arshad L, Bukhari SNA. Exploring the immunomodulatory and anticancer properties of zerumbone. Food Funct. 2017;8(10):3410-31.

11. Haque MA, Jantan I, Harikrishnan $\mathrm{H}$. Zerumbone suppresses the activation of inflammatory mediators in LPS-stimulated U937 macrophages through MyD88-dependent NF-KB/MAPK/PI3K-Akt signaling pathways. Int Immunopharmacol. 2018;55:312-22.

12. Keong YS, Alitheen NB, Mustafa S, Aziz SA, Rahman MA, Ali AM. Immunomodulatory effects of zerumbone isolated from roots of Zingiber zerumbet. Pakistan J Pharm Sc. 2010;23:75-82.

13. Haque MA, Jantan I. Recent updates on the phytochemistry, pharmacological, and toxicological activities of Zingiber zerumbet (L.) roscoe ex Sm. Curr Pharm Biotechnol. 2017;18(9):696-720.

14. Sulaiman MR, Mohamad TAST, Mossadeq WMS, Moin S, Yusof M, Mokhtar AF, Zakaria ZA, Israf DA, Lajis N. Antinociceptive activity of the essential oil of Zingiber zerumbet. Planta Med. 2010;76:107-12.

15. Singh CB, Nongalleima K, Brojendrosingh S, Ningombam S, Lokendrajit N, Singh L. Biological and chemical properties of Zingiber zerumbet smith: a review. Phytochem Rev. 2012;11:113-25.

16. Jantan I, Goh SH. Essential oils of Cinnamomum species from peninsular Malaysia. J Essent Oil Res. 1992;4:161-71.

17. Kovats ES. Gas chromatographic characterization of organic substances in the retention index system. Adv Chromatogr. 1965;1: 229-47.

18. Arshad L, Jantan I, Bukhari SNA, Jamil S. Inhibitory effects of a, $\beta$ unsaturated carbonyl-based compounds and their pyrazoline derivatives on the phagocytosis of human neutrophils. Med Chem Res. 2018;27(5): 1460-71.

19. Jantan I, Illangkovan M, Yuandani Mohamad HF. Correlation between the major components of Phyllanthus amarus and Phyllanthus urinaria and their inhibitory effects on phagocytic activity of human nueutrophils. BMC Complement Altern Med. 2014;14:429.

20. Arshad L, Jantan I, Bukhari SNA, Fauzi MB. 3, 5-bis [4-(diethoxymethyl) benzylidene]-1-methyl-piperidin-4-one, a novel curcumin analogue, inhibits cellular and humoral immune responses in male balb/c mice. Curr Pharm Biotechnol. 2018;19(6):468-82.

21. Spisani S, Vanzini G, Traniello S. Inhibition of human leucocytes locomotion by anti-inflammatory drugs. Cell Mol Life Sci. 1979;35(6): 803-4.

22. Harun NH, Septama AW, Jantan I. Immunomodulatory effects of selected Malaysian plants on the CD18/11a expression and phagocytosis activities of leukocytes. Asian Pac J Trop Biomed. 2015 5(1):48-53.

23. Jyothilakshmi M, Jyothis M, Latha MS. Anti-inflammatory efficacy of the rhizome of Zingiber zerumbet-an in vitro study using THP1 cell line. J Med Plants Stud. 2016:4:103-6.

24. Kim D, Haynes CL. The role of p38 MAPK in neutrophil functions: single cell chemotaxis and surface marker expression. Analyst. 2013; 138:6826-33.

25. Kummer R, Estevão-Silva CF, Bastos RL, Rocha BA, Spironello RA, Yamada AN, Bersani-Amado CA, Cuman RKN. Alpha-pinene reduces in vitro and in vivo leukocyte migration during acute inflammation. Inter J Appl Res Nat Prod. 2008;8(4):12-7.

26. de Melo GAN, Grespan R, Fonseca JP, Farinha TO, da Silva EL, Romero AL, Bersani-Amado CA, Cuman RKN. Inhibitory effects of ginger (Zingiber officinale roscoe) essential oil on leukocyte migration in vivo and in vitro. J Nat Med. 2011;65:241-6.

27. Yamada AN, Grespan R, Yamada ÁT, Silva EL, Silva-Filho SE, Damião MJ, de Oliveira Dalalio MM, Bersani-Amado CA, Cuman RKN. Antiinflammatory activity of Ocimum americanum L. essential oil in experimental model of zymosan-induced arthritis. Am J Chin Med. 2013 41:913-26.

28. Lynn W, Raetz C, Qureshi N, Golenbock D. Lipopolysaccharide-induced stimulation of CD11b/CD18 expression on neutrophils. Evidence of specific receptor-based response and inhibition by lipid A-based antagonists. J Immunol. 1991;147:3072-9.

29. Zhong X, Li X, Liu F, Tan H, Shang D. Omentin inhibits TNF-a-induced expression of adhesion molecules in endothelial cells via ERK/NF-KB pathway. Biochem Biophys Res Commun. 2012;425:401-6. 
30. May RC, Machesky LM. Phagocytosis and the actin cytoskeleton. J Cell Sci. 2001;114:1061-77.

31. Fialkow L, Wang Y, Downey GP. Reactive oxygen and nitrogen species as signaling molecules regulating neutrophil function. Free Radic Biol Med. 2007:42:153-64.

32. Briggs RT, Robinson JM, Karnovsky ML, Karnovsky MJ. Superoxide production by polymorphonuclear leukocytes. J Histochem. 1998;84:371-6.

33. Nag A, Bandyopadhyay M, Mukherjee A. Antioxidant activities and cytotoxicity of Zingiber zerumbet (L.) smith rhizome. J Pharmacogn Phytochem. 2013;2:102-8.

\section{Publisher's Note}

Springer Nature remains neutral with regard to jurisdictional claims in published maps and institutional affiliations.

Ready to submit your research? Choose BMC and benefit from:

- fast, convenient online submission

- thorough peer review by experienced researchers in your field

- rapid publication on acceptance

- support for research data, including large and complex data types

- gold Open Access which fosters wider collaboration and increased citations

- maximum visibility for your research: over $100 \mathrm{M}$ website views per year

At $\mathrm{BMC}$, research is always in progress.

Learn more biomedcentral.com/submissions 